\title{
The spatial distribution of leprosy in four villages in Bangladesh: An observational study
} EAJ Fischer*1, D Pahan², SK Chowdhury², L Oskam³ and JH Richardus ${ }^{1}$

\author{
Address: ${ }^{1}$ Department of Public Health, Erasmus MC, University Medical Center Rotterdam, Rotterdam, The Netherlands, ${ }^{2}$ Rural Health Program, \\ Leprosy Mission Bangladesh, Nilphamari, Bangladesh and ${ }^{3}$ KIT Biomedical Research, Royal Tropical Institute, Amsterdam, The Netherlands \\ Email: EAJ Fischer* - egil.fischer@wur.nl; D Pahan - chd@dblm.tlmbangladesh.org; SK Chowdhury - chd@dblm.tlmbangladesh.org; \\ L Oskam - l.oskam@kit.nl; JH Richardus - j.richardus@erasmusmc.nl \\ * Corresponding author
}

Published: 23 September 2008

BMC Infectious Diseases 2008, 8:125 doi:10.1 186/1471-2334-8-125
Received: 24 December 2007

Accepted: 23 September 2008

This article is available from: http://www.biomedcentral.com/I47I-2334/8/I25

(C) 2008 Fischer et al; licensee BioMed Central Ltd.

This is an Open Access article distributed under the terms of the Creative Commons Attribution License (http://creativecommons.org/licenses/by/2.0), which permits unrestricted use, distribution, and reproduction in any medium, provided the original work is properly cited.

\begin{abstract}
Background: There is a higher case-detection rate for leprosy among spatially proximate contacts such as household members and neighbors. Spatial information regarding the clustering of leprosy can be used to improve intervention strategies. Identifying high-risk areas within villages around known cases can be helpful in finding new cases.

Methods: Using geographic information systems, we created digital maps of four villages in a highly endemic area in northwest Bangladesh. The villages were surveyed three times over four years. The spatial pattern of the compounds - a small group of houses - was analyzed, and we looked for spatial clusters of leprosy cases.

Results: The four villages had a total population of 4,123. There were 14 previously treated patients and we identified 19 new leprosy patients during the observation period. However, we found no spatial clusters with a probability significantly different from the null hypothesis of random occurrence.

Conclusion: Spatial analysis at the microlevel of villages in highly endemic areas does not appear to be useful for identifying clusters of patients. The search for clustering should be extended to a higher aggregation level, such as the subdistrict or regional level. Additionally, in highly endemic areas, it appears to be more effective to target complete villages for contact tracing, rather than narrowly defined contact groups such as households.
\end{abstract}

\section{Background}

Identifying individuals with increased exposure to $\mathrm{Myco-}$ bacterium leprae, the causative agent of leprosy, enhances the possibility of prevention or early diagnosis. Several studies have shown that household members and neighbors have an increased risk of leprosy [1-3], making them desirable targets for interventions such as preventive treatment $[2,4]$. A study in Indonesia identified spatial clusters of cases on islands with extremely high incidence [1]. Spa- tial information can be used to improve the discovery of new cases and other interventions in high incidence areas [5].

In the Nilphamari district in Bangladesh, household members and close neighbors have an increased risk of contracting leprosy when compared with neighbors of neighbors and social contacts [2]. However, new cases among neighbors of neighbors and social contacts were 
still over three times more likely than in the general population $[2,6]$. Because neighbors of neighbors and social contacts still live near patients [7], exposure to M. leprae is likely to cluster at a spatial level smaller than villages. Moet et al. [2] have shown that leprosy is aggregated at the household level and for adjacent neighbors, but the extent to which leprosy cases are spatially aggregated within complete villages is not known.

We believe that identifying neighborhoods or areas with many previously undetected cases will improve efforts to find new cases. Here, we report on the spatial distribution of prevalent cases and cases that were found during two follow-up surveys with two-year intervals in four villages within in a highly endemic area. We attempted to identify spatial clusters of leprosy cases within these four villages using a spatial scan statistic $[8,9]$.

\section{Methods}

\section{Study population and survey}

As part of a larger previously conducted study [10], 20 administrative areas were randomly selected from two districts in northwest Bangladesh. The survey started at the northern borders of the areas and included all of the people present until approximately 1,000 people were examined. The groups were surveyed between November 2002 and February 2003. During the survey, people were asked about leprosy symptoms and a body check was performed. Those who were suspected of having leprosy were referred to a senior leprosy control officer and a doctor for confirmation. If the disease was confirmed, regular treatment was offered. The inhabitants who participated in the first survey were visited in the same months in 2004-2005 and 2006-2007, if they still lived in the same area. So that our results may be thoroughly understood, we have provided a summary of our survey methods. A more extensive description of the survey can be found elsewhere [6].

For the current study, we selected four groups out of the 20 groups, all within the Nilphamari district, because these were easily accessible. An overview map of the Nilphamari indicating the four selected villages is presented in figure 1 . We selected the sample populations with the highest number of cases during intake; three of the four selected population samples also had a high prevalence of anti-M. leprae IgM antibodies, which is thought to indicate increased exposure [6], most likely leading to an increased incidence of leprosy. Three groups were selected from a rural area and one from an urban area.

\section{Map preparation and census data}

Maps were prepared in January 2006 using handheld global positioning system (GPS) units (Geko 201, Garmin, USA). The maps were drawn in ArcGIS 9.1 (ESRI, USA). Coordinates were collected for the compounds and roads, and for some geographic features such as schools, mosques, and bodies of water. Compounds are small groups of 1 to 10 houses, often inhabited by one family. Digital maps were drawn using these geo-references and hand-drawn maps. The calculated centroids of compounds were used as census points. Participants were attributed to the nearest census points.

We recorded participants' death and migration since the 2003 study intake. If we were able to obtain the information, migrated or deceased people were attributed to the compound in which they lived during intake.

\section{Statistical analysis}

The spatial pattern of the compounds was determined by the average nearest neighbor index (ANNI). An ANNI smaller than 1 indicates a clustered pattern of compounds when compared with a random model [11].

The groups were scanned using spatial scan statistic to detect high prevalence clusters of cases. The scans were performed for purely spatial data, and imposed circular windows with flexible radii on all of the locations in the area. The number of cases within a window was assumed to follow a Poisson distribution under the null hypothesis. For each window, the likelihood was calculated for the observed cases and the expected cases under the null hypothesis. The window with the highest likelihood constituted the most likely cluster. The distribution of the maximum likelihood was determined by many random replications of the dataset under the null hypothesis. The $p$ value was then calculated by comparing the rank of the maximum likelihood of the real dataset with the ranks of the maximum likelihoods of the random datasets [8]. The analyses were performed with SatScan version 7.0 [9].

\section{Ethical clearance}

Ethical clearance was obtained from the ethical review committee of the Bangladesh Medical Research Council (reference numbers BMRC/ERC/2001-2004/799 and BMRC/ERC/2004-2007/1397).

\section{Results \\ Area characteristics}

Group A lived in an area near the Indian border. The total area of the village was $1.04 \mathrm{~km}^{2}$. The village contained two schools for secondary education and a local police headquarters.

Group B was reached by crossing a large river. The east and west borders of the village were delimited by the river embankments. The village contained no brick or concrete buildings, except for a mosque and a primary school. The total area of the village was $1.39 \mathrm{~km}^{2}$. It bordered another village directly to the north. 


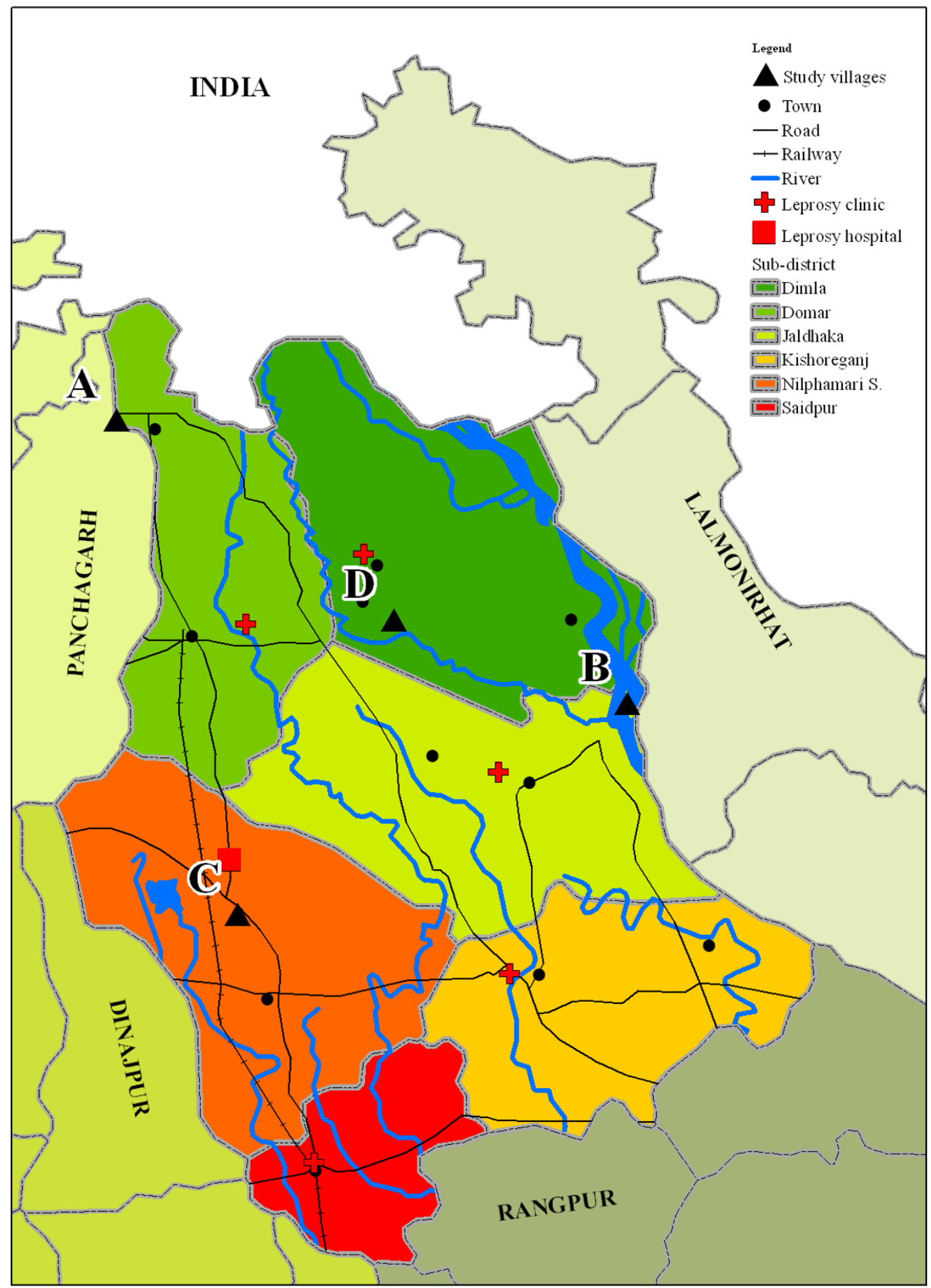

Figure I

An overview map of the Nilphamari district showing several geographic features, such as towns, roads and rivers. The four selected villages are indicated by black triangles. 
The urban group $\mathrm{C}$ was located at the edge of the district capital and contained the largest population of the three groups. This urban ward had an area of only $0.31 \mathrm{~km}^{2}$. Most of the compounds were north of an asphalt road leading to the town center. Approximately one-third of the houses were built of brick or concrete. The office building of a large regional nongovernmental organization was located on the south border.

Group D was located near a cluster of shops situated at the crossing of two major roads coming from the district capital and a nearby town. A lake surrounding by marshes bordered the village to the south. At $1.82 \mathrm{~km}^{2}$, this village had the largest area of the four groups. The village contained two primary schools, two mosques, and several Hindu shrines.

\section{Study population}

The total study population consisted of 4,123 people. The mean age at intake was 21.8 years. The proportion of children under 15 years was on average 0.54. People who were not at home during intake were not included in the study, which is the most likely explanation for the uneven sex ratios of groups $\mathrm{A}, \mathrm{C}$, and D (Table 1). In these groups, males were more likely than females to be at work in another area during the days on which intake took place. The people of group B worked in the fields near their home; thus, males and females were evenly included.

The average compound size of 4.6 persons per compound was comparable with the census data on average household size for rural Bangladesh [12]. Compounds comprised 1.9 houses, on average.
At intake, 14 persons were known to have been released from treatment for leprosy prior to the study intake. Furthermore, there were seven newly diagnosed cases of leprosy. Of the seven cases, all had paucibacillary (PB) leprosy. There were no cases of multibacillary (MB) leprosy. After two years, six new cases were detected; one had $\mathrm{MB}$ leprosy, and the other five were diagnosed with $\mathrm{PB}$ leprosy. Finally, four years after study intake, another six new cases were detected, all of which were PB leprosy. The proportion of $\mathrm{PB}$ cases was not unexpected, given that the proportion of $\mathrm{PB}$ cases among the total cases detected in this district was approximately 0.8 . During surveys, such as the one used in this study, the proportion of PB cases is higher than among voluntarily reported cases, because many less-severe cases can remain otherwise undetected.

After two years, a total of 265 persons were lost to followup due to death (37) or migration (228). As far as we could determine either by registration at the clinics or by asking relatives, none of the deceased people had experienced clinical leprosy. One person who had migrated was diagnosed with leprosy at intake in group A, and could be attributed to the compound in which he was living at intake. Thirty persons moved within the areas; none of them had leprosy. At the time of the writing of this report, further details concerning persons lost to follow-up were not yet available.

\section{Spatial patterns}

Compounds were aggregated in space (Table 2). ANNI ranged between 0.30 and 0.56 . Eyeballing of Figure 2 intuitively confirms the aggregated spatial pattern of the

Table I: Study population, demographics, and number of newly detected leprosy cases in four sample populations.

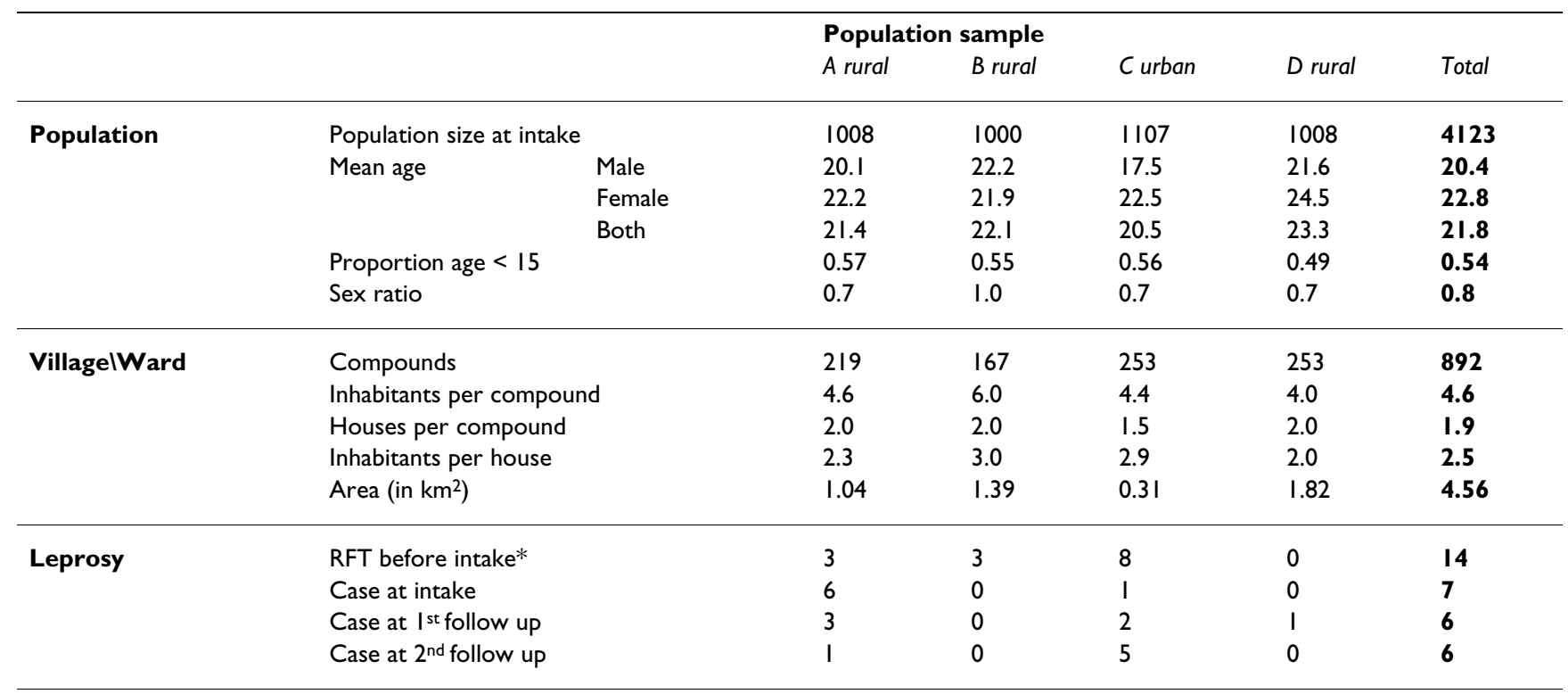

*Released from leprosy treatment before the first survey. 


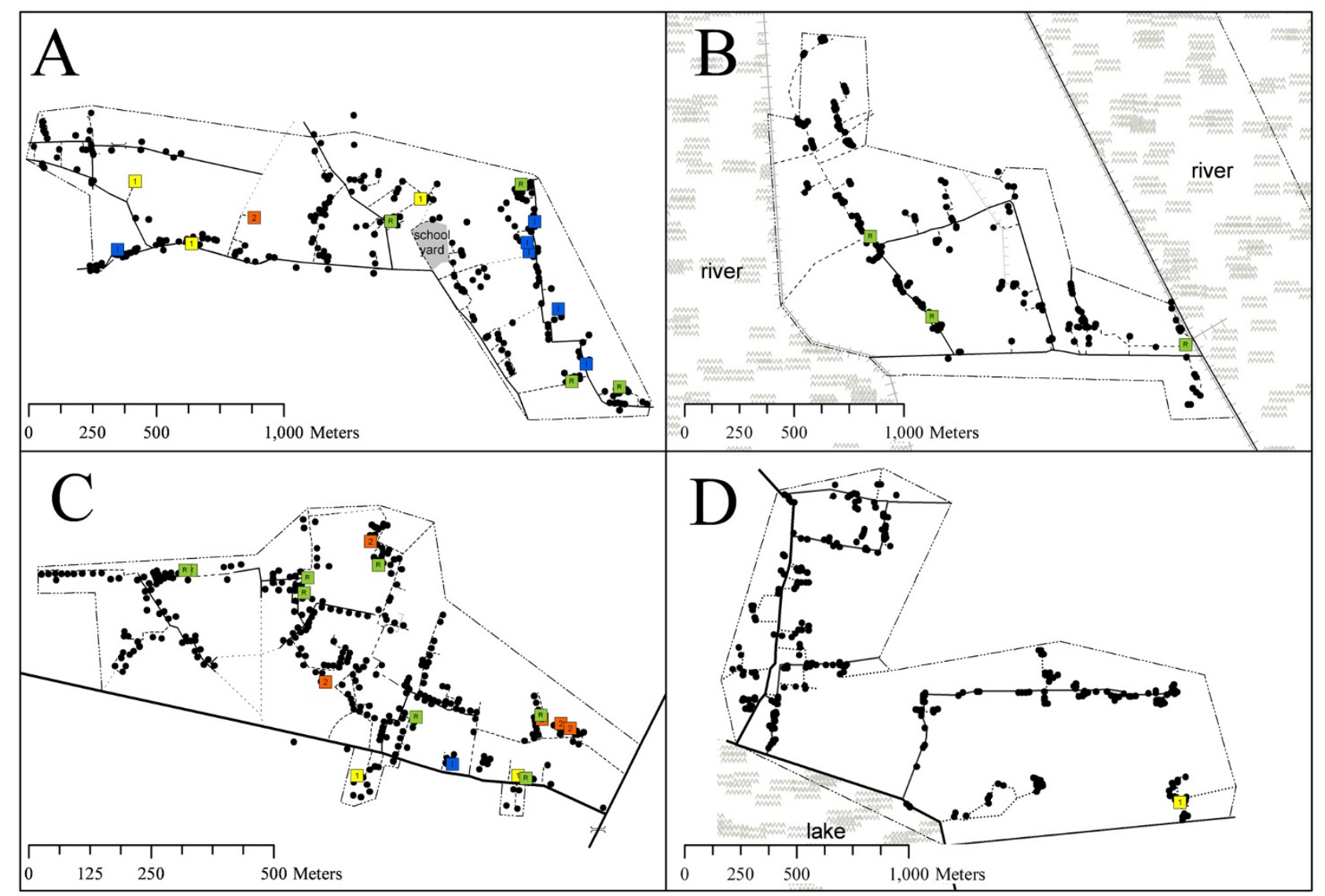

\section{Legend}

[a Released from treatment before intake of study

Intake 1st Follow up

2nd Follow up

- Leprosy free compound

Figure 2

Newly detected cases by moment of detection (e.g. before intake, at intake, first follow up or second follow up) in four sample group areas. Compounds are depicted by a black dot. The dash-dotted ( $\cup-)$ line indicates the village or ward border. Other lines indicate roads, canals and river embankments. Compounds outside these borders are not included in the study, but some are shown on the maps to indicate the closeness of other villages.

Table 2: Spatial patterns of compounds and new cases in each population

\begin{tabular}{|c|c|c|c|c|c|c|c|c|c|c|}
\hline & \multirow{2}{*}{\multicolumn{2}{|c|}{ Clustering of compounds }} & \multicolumn{8}{|c|}{ Clusters of cases } \\
\hline & & & \multicolumn{2}{|c|}{ All cases } & \multicolumn{2}{|c|}{ At intake } & \multicolumn{2}{|c|}{ Ist follow up } & \multicolumn{2}{|c|}{$2^{\text {nd }}$ follow up } \\
\hline & ANNIa & Z-score & LLR $^{\mathrm{b}}$ & $p^{c}$ & LLR $^{b}$ & $p^{c}$ & LLR $^{\mathrm{b}}$ & $p^{c}$ & LLR $^{\mathrm{b}}$ & $p^{c}$ \\
\hline$A^{d}$ & 0.42 & -17.6 & 3.2 & 0.60 & 5.9 & 0.13 & 3.0 & 0.51 & - & - \\
\hline$B^{d}$ & 0.30 & -17.8 & 3.4 & 0.52 & - & - & - & - & - & - \\
\hline C & 0.56 & -14.7 & 4.2 & 0.81 & 4.5 & 0.18 & 1.8 & 0.65 & 4.4 & 0.14 \\
\hline$D^{d}$ & 0.30 & -22.9 & - & - & - & - & - & - & - & - \\
\hline
\end{tabular}

a Average Nearest Neighbor Index.

b Log likelihood ratio.

c Determined by 999 Monte Carlo replications.

d No calculation of log-likelihood ratio - and thus p-value - possible for none or I case. 
compounds, which were positioned in small groups and along the roads.

The spatial scan statistic determined the location of the most likely cluster for each area. None of the four clusters were significantly different $(p<0.05)$ from the Poisson model, shown in Table 2.

\section{Discussion}

We could not identify clusters of leprosy at this spatial microlevel of $0.32-1.82 \mathrm{~km}^{2}$, an area equivalent to a town ward or village. Thus, either at this level spatial clustering does not occur, or the force with which leprosy clusters is not strong enough to reveal spatial clustering using only a few population samples with a moderate number of cases. One would need to observe many of these areas (villages) to identify a limited number of possible clusters. Both of these explanations call into question the value of attempting to identify leprosy clusters at this level.

Spatial clustering of leprosy has been found on Indonesian islands with extremely high numbers of previously undetected cases $[1,13]$. The power of the statistical tests for clustering was thus much greater than in our study. Furthermore, the studies by Bakker et al. [13] were conducted among populations living on remote islands. These island populations had a contact pattern that differed from our study population. The population in northwest Bangladesh is not confined to an archipelago of small islands, but lives in an easily accessible and densely populated area of the Indian subcontinent.

Although members of the same household as a person with leprosy have a much higher relative risk of contracting leprosy [2], the number of nonhousehold contacts (such as relatives and social contacts) is many times higher than that of household contacts [14]. However, as we have illustrated, we found no clusters of leprosy within the limited number of villages that we observed.

It is not easy to identify clusters of patients using spatial analysis at the microlevel of villages in highly endemic areas, compared with higher levels. In a separate paper, we found spatial clustering at the district level in the same area in Bangladesh [15]. In addition, Moet et al. [2] found large differences in previously undetected prevalence in the 20 population samples. Some of these population samples (e.g., group A in this study) had a previously undetected prevalence equal to that of close contacts [2].

\section{Conclusion}

The search for clustering should be extended to higher aggregation levels, such as subdistrict or regional levels. Thus, in highly endemic areas, it appears to be more effec- tive to target complete villages for contact tracing, rather than narrowly defined contact groups such as households.

\section{Abbreviations}

ANNI: average nearest neighbor index; GIS: geographic information system; GPS: global positioning system; MB: multibacillary; PB: paucibacillary.

\section{Competing interests}

The authors declare that they have no competing interests.

\section{Authors' contributions}

EF was involved in all aspects of the research and drafting of this manuscript. DP and SC contributed to the set-up, planning, and conduction of data collection, and commented on the manuscript. LO was involved in the conception and design of the study, and also in drafting of the manuscript. JR was involved in the conception and design of the study, as well as the analysis, and contributed considerably to the drafting of the manuscript.

\section{Acknowledgements}

The leprosy control supervisors of the Rural Health Program (formerly DBLM) in Nilphamari are gratefully thanked for their efforts. The inhabitants of the study areas are thanked for their hospitality and cooperation. We acknowledge the important comments raised by two reviewers, which helped to improve an earlier version of this manuscript.

We acknowledge the American Leprosy Missions for financial support of this study. EF is thankful for the financial support received from The Netherlands Leprosy Relief.

\section{References}

I. Bakker MI, May L, Hatta M, Kwenang A, Klatser PR, Oskam L, Houwing-Duistermaat J]: Genetic, household and spatial clustering of leprosy on an island in Indonesia: a population-based study. BMC Medical Genetics 2005, 6:40.

2. Moet FJ, Pahan D, Schuring RP, Oskam L, Richardus JH: Physical distance, genetic relationship, age, and leprosy classification are independent risk factors for leprosy in contacts of patients with leprosy. Journal of Infectious diseases 2006, 193(3):346-353.

3. Van Beers SM, Hatta M, Klatser PR: Patient contact is the major determinant in incident leprosy: implications for future control. Int J Lepr Other Mycobact Dis 1999, 67(2): I 19-128.

4. Bakker MI, Hatta M, Kwenang A, Van Benthem BH, Van Beers SM, Klatser PR, Oskam L: Prevention of leprosy using rifampicin as chemoprophylaxis. Am J Trop Med Hyg 2005, 72(4):443-448.

5. De Souza Dias MC, Dias GH, Nobre ML: The use of Geographical Information System (GIS) to improve active leprosy case finding campaigns in the Municipality of Mossoro, Rio Grande do Norte State, Brazil. Leprosy Review 2007, 78(3):261-269.

6. Moet FJ, Schuring R, Pahan D, Oskam L, Richardus JH: The prevalence of previously undiagnosed leprosy in the general population and in close contacts of leprosy patients in northwest Bangladesh. PLoS Neglected Tropical Diseases 2008, 2(2):el 98.

7. Hoeven TA, Fischer EAJ, Pahan D, Richardus JH: Social distance and spatial distance are not the same, observations on the use of GIS in leprosy epidemiology. Epidemiology and Infection .

8. Kulldorff M: Bernoulli and Poisson Models: A spatial scan statistic. Communications in Statistics:Theory and Methods 1997, 26: $148 \mid-1496$. 
9. Kulldorff M, Information Management Services I: SaTScan, Software for the spatial and space-time scan statistics. 4.0 .3 edition. 2003.

10. Moet FJ, Oskam L, Faber R, Pahan D, Richardus JH: A study on transmission and a trial of chemoprophylaxis in contacts of leprosy patients: design, methodology and recruitment findings of COLEP. Leprosy Review 2004, 75(4):376-388.

11. Ebdon D: Statistics in Geographics. 2nd, revised edition. Oxford: Blackwell; 1986.

12. Ebdon D: Statistical Yearbook of Bangladesh. Volume I. Dhaka: Bangladesh Bureau of Statistics, Statistics division, Ministery of Planning, Government of the People's Republic of Bangladesh; 1995:646.

13. Bakker MI, Hatta M, Kwenang A, Faber WR, van Beers SM, Klatser $\mathrm{PR}$, Oskam L: Population survey to determine risk factors for Mycobacterium leprae transmission and infection. International Journal of Epidemiology 2004, 33(6): I329-1336.

14. Cellona RV, Walsh GP, Fajardo TT Jr, Abalos RM, dela Cruz EC Guido-Villahermosa L, Felicio-Balagon MV, Steenbergen GJ, Douglas $\mathrm{JT}$ : Cross-sectional assessment of ELISA reactivity in leprosy patients, contacts, and normal population using the semisynthetic antigen natural disaccharide octyl bovine serum albumin (ND-O-BSA) in Cebu, The Philippines. Int J Lepr Other Mycobact Dis 1993, 6I(2): 192-198.

15. Fischer EAJ, Pahan D, Chowdhury SK, Richardus JH: The spatial distribution of leprosy during I5-years of a leprosy control program in Bangladesh: An observational study. BMC Infect Dis 2008, 8(I): 126 .

\section{Pre-publication history}

The pre-publication history for this paper can be accessed here:

http://www.biomedcentral.com/1471-2334/8/125/pre pub

Publish with Bio Med Central and every scientist can read your work free of charge

"BioMed Central will be the most significant development for disseminating the results of biomedical research in our lifetime. "

Sir Paul Nurse, Cancer Research UK

Your research papers will be:

- available free of charge to the entire biomedical community

- peer reviewed and published immediately upon acceptance

- cited in PubMed and archived on PubMed Central

- yours - you keep the copyright

Submit your manuscript here:

http://www.biomedcentral.com/info/publishing_adv.asp 